\title{
Exposure to Multiwalled Carbon Nanotubes and Allergen Promotes Early- and Late-Phase Increases in Airway Resistance in Mice
}

\author{
Nobuaki Mizutani, ${ }^{*, a}$ Takeshi Nabe, ${ }^{b}$ and Shin Yoshino ${ }^{a}$ \\ ${ }^{a}$ Department of Pharmacology, Kobe Pharmaceutical University; 4-19-1 Motoyamakita, Higashinada, Kobe \\ 658-8558, Japan: and ${ }^{b}$ Department of Pharmacology, Kyoto Pharmaceutical University; 5 Nakauchi, Misasagi, \\ Yamashina, Kyoto 607-8414, Japan. Received April 19, 2012; accepted September 12, 2012
}

The facilitating effects of multiwalled carbon nanotubes (MWCNT) on allergic asthma have not been sufficiently examined, although MWCNT appear to significantly increase the risk of health problems from occupational or environmental exposure. In this study, we examined whether sensitization by the combination of MWCNT with ovalbumin (OVA) promotes allergic asthmatic responses. BALB/c mice administered vehicle, MWCNT, OVA, or MWCNT+OVA through an intranasal route were challenged with OVA intratracheally four times. In the MWCNT+OVA group, the fourth challenge caused not only early- but also latephase increases in airway resistance, although these responses were not observed in the vehicle, MWCNT, or OVA group; furthermore, the extents of the early and late responses were comparable to those in mice systemically sensitized with OVA+alum. Sensitization with MWCNT and OVA promoted airway inflammation and goblet cell hyperplasia in the lung compared with the vehicle, MWCNT or OVA group. In addition, adjuvant activity for OVA-specific immunoglobulin E (IgE), IgG1, and IgG2a production in serum and increased levels of interleukin-4 (IL-4), IL-5, IL-13, and IL-17 in the lung tissue were observed. In conclusion, these results suggest that exposure to MWCNT and antigen can induce a biphasic increase in airway resistance, airway inflammation, goblet cell hyperplasia, and the production of antigen-specific antibodies. This study highlights the risk of exposure to a combination of MWCNT with antigen.

Key words carbon nanotube; allergic asthma; airway resistance; goblet cell hyperplasia; adjuvant activity

Allergic asthma is a chronic type of airway inflammation characterized by reversible airway obstruction and goblet cell hyperplasia associated with elevated levels of allergen-specific immunoglobulin E (IgE). ${ }^{1-3)}$ The prevalence of asthma has increased markedly over the past 3 decades, and may be due to changes in environmental factors, including indoor and outdoor air pollution. ${ }^{4,5}$ Relatively few investigations on the environmental exacerbating factors of the pathology have been conducted, although intensive experiments have accumulated evidence regarding the molecular mechanisms of therapeutic targets. The former type of research should be focused on, since large environmental changes may occur throughout the world in the future.

Nanotechnology is now advancing at an incredible pace, such that it has created an alternative industrial revolution over the past few years. ${ }^{6)}$ Consistent with this, the use of engineered nanomaterials has been rapidly increasing in commercial applications. As these materials have become more widespread, many questions have arisen regarding the effects of these materials as inhalable toxicants. Among several different types of nanomaterials, carbon nanotubes (CNT) are one of the most attractive materials because of their unique physical and chemical characteristics, including their size $(1-20 \mathrm{~nm}$ width and many micrometers in length), strength, and surface chemistry. ${ }^{7,8)}$ However, CNT show marked cytotoxicity, such as the induction of oxidative stress, cellular proliferation, and apoptosis/necrosis in several types of cell in vitro. ${ }^{9-12)}$ There is in vivo evidence implicating CNT in the induction of inflammatory lung disorders, including oxidative tissue injury ${ }^{13,14)}$; however, less research has been conducted to examine the effects of CNT on allergic respiratory disorders, including asthma as an exacerbating factor.

The authors declare no conflict of interest.
We have reported a mouse model showing early- and latephase increases in airway resistance and goblet cell hyperplasia by systemic sensitization with $\mathrm{Al}(\mathrm{OH})_{3}$ plus ovalbumin (OVA) as an allergen and repeatedly allergen challenge. ${ }^{15,16)}$ In the present study, we hypothesized that sensitization by the co-administration of multiwalled CNT (MWCNT) with allergen promote allergic asthmatic responses in mice, indicating that this research has important implications for understanding the health risks of exposure to MWCNT and allergen. Therefore, we intranasally administered vehicle, MWCNT, OVA, or MWCNT+OVA to mice, which were then challenged repeatedly by the intratracheal instillation of OVA. Using this experiment protocol, we examined whether MWCNT exacerbated an antigen-induced biphasic increase in airway resistance, airway inflammation, goblet cell hyperplasia, cytokine production in the lung tissue, and the production of antigenspecific antibodies (IgE, IgG1, and IgG2a) in serum.

\section{MATERIALS AND METHODS}

Animals Male 7-wk-old BALB/c mice were obtained from Japan SLC. These mice were maintained in a temperature-controlled environment with free access to standard rodent chow and water. The first sensitization was started 1 wk after arrival.

All of the experimental procedures were approved by the Experimental Animal Research Committee at Kobe Pharmaceutical University.

Reagents MWCNT (diameter: 10-15 nm and length: $0.1-10 \mu \mathrm{m})$ and OVA (grade V) were purchased from SigmaAldrich (St. Louis, MO, U.S.A.). MWCNT were suspended in $0.1 \%$ Tween 20 in saline, and then the solution was sonicated for $30 \mathrm{~min}$ immediately before use. It has been demonstrated that well-dispersed CNT are less toxic than agglomerated or 
A
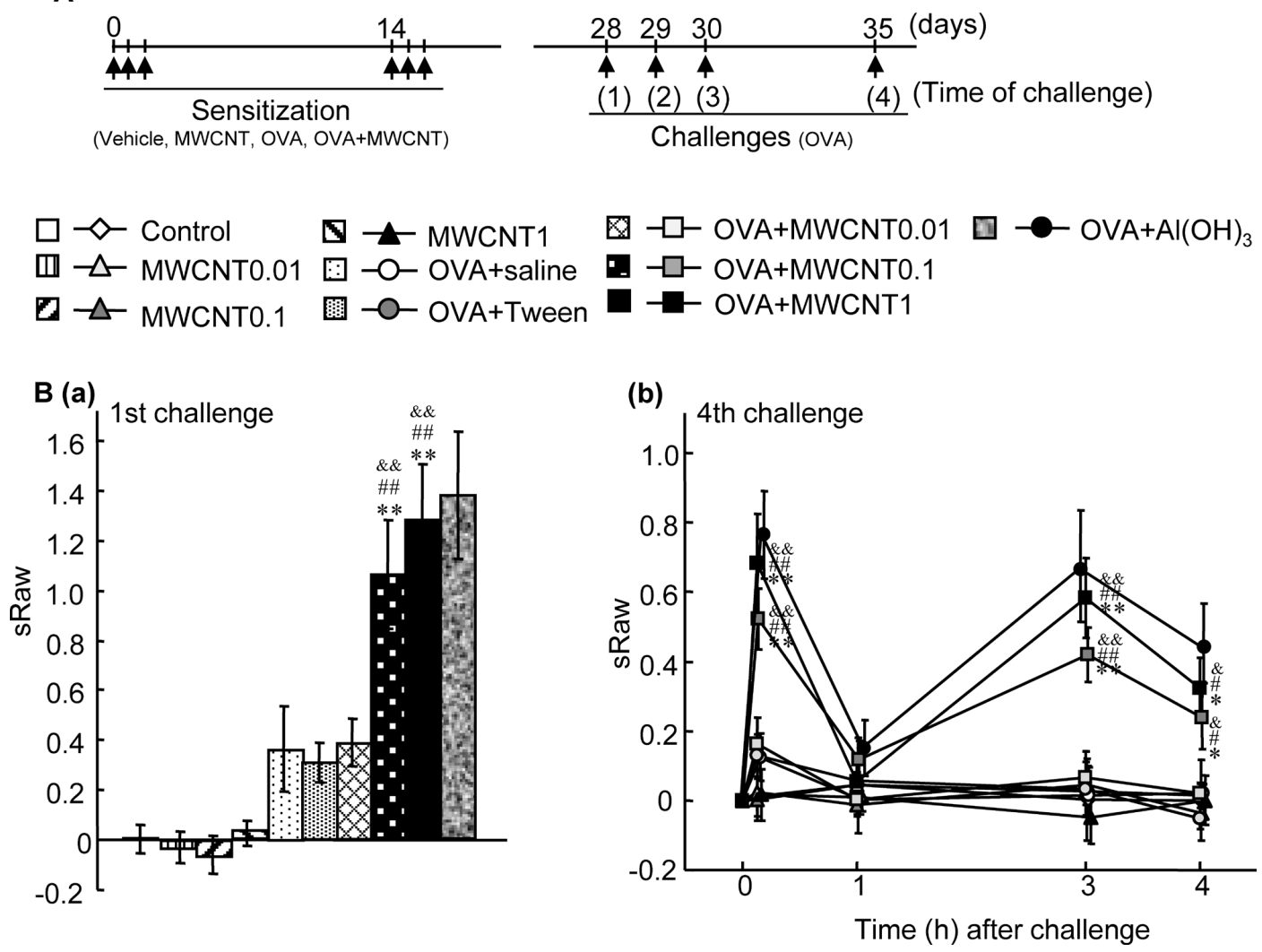

Fig. 1. Effect of MWCNT on Early- and Late-Phase Increases in Airway Resistance after the Antigen Challenges

(A) Experimental protocol for sensitization with MWCNT and OVA and challenge with OVA in mice. (B) Changes in sRaw after the first (a) and fourth (b) challenges in mice sensitized with MWCNT and OVA. Results of Fig. 1Ba indicate those at 10 min after the first challenge. Each value is the mean \pm S.E.M. of $5-7$ animals. ${ }^{*} p<0.05$ and ${ }_{* *} p<0.01$ compared with control group. ${ }^{\#} p<0.05$ and ${ }^{\# \#} p<0.01$ compared with OVA+Tween group. ${ }^{\&} p<0.05$ and ${ }^{\& \&} p<0.01$ compared with MWCNT group.

pellet CNT in a mesothelioma cell line ${ }^{17)}$; thus, the degree of agglomeration is important for evaluation of the adverse effects of CNT. Tween 20 is a stable and relatively nontoxic detergent and emulsifier used in a number of pharmacological applications; indeed, when three types of dispersion agent (phosphate-buffered saline (PBS), PBS+dimethyl sulfoxide, and PBS+Tween 20) were used, PBS+Tween 20 was the most effective dispersion agent for $\mathrm{CNT}^{18)}$; therefore, we used Tween 20 for dispersing MWCNT. Nevertheless, MWCNT occur, at least in part, in agglomerated forms due to van der Waals forces.

Sensitization and Challenge As shown in Fig. 1A, $\mathrm{BALB} / \mathrm{c}$ mice were sensitized on days $0,1,2,14,15$, and 16 under anesthesia with escain (Mylan, Osaka, Japan) with saline (Control), 0.01-1 mg MWCNT/mL in Tween 20 (MWCNT0.01, MWCNT0.1, and MWCNT1), $2.5 \mathrm{mg}$ OVA/ $\mathrm{mL}$ in saline (OVA+saline), $2.5 \mathrm{mg} \mathrm{OVA} / \mathrm{mL}$ in Tween 20 (OVA+Tween), $2.5 \mathrm{mg} \quad \mathrm{OVA} / 0.01-1 \mathrm{mg} \quad \mathrm{MWCNT} / \mathrm{mL}$ in Tween 20 (OVA+MWCNT0.01, OVA+MWCNT0.1, and OVA+MWCNT1) in a volume of $30 \mu \mathrm{L}$ through an intranasal route. Subsequently, the mice were challenged on days 28, 29, 30 , and 35 with $1 \%$ OVA in a volume of $20 \mu \mathrm{L}$ by intratracheal administration. ${ }^{16)}$

Furthermore, systemic sensitization with OVA+alum was performed according to a previously described method. ${ }^{16}$ ) $\mathrm{BALB} / \mathrm{c}$ mice were sensitized by intraperitoneal injection with OVA adsorbed to alum (Wako Pure Chemical Industries, Ltd., Osaka, Japan). OVA was used at a dose of $50 \mu \mathrm{g}$ adsorbed to
$1 \mathrm{mg}$ alum $/ 0.2 \mathrm{~mL} / \mathrm{mouse}$ on days 0 and 14 . The sensitized mice were challenged on days $28,29,30$, and 35 with $1 \%$ OVA in a volume of $20 \mu \mathrm{L}$ by intratracheal administration.

Measurement of Airway Resistance To evaluate the degree of airway resistance, specific airway resistance (sRaw; $\left.\mathrm{cmH}_{2} \mathrm{O} \times \mathrm{mL} /(\mathrm{mL} / \mathrm{s})\right)$ was measured in conscious mice before and $10 \mathrm{~min}$ to $4 \mathrm{~h}$ after the antigen challenges using a twochambered, double-flow plethysmograph system (Pulmous-I; MIPS, Osaka, Japan) according to the method of Pennock et al. ${ }^{19)}$

Analysis of Cells Recovered by Bronchoalveolar Lavage (BAL) To evaluate airway inflammation, we examined the accumulation of inflammatory cells in BAL fluid (BALF). Animals were killed with diethyl ether. The trachea was cannulated, and the left bronchi were tied for histological examination. The right air lumen was then washed twice with $0.5 \mathrm{~mL}$ Hank's balanced salt solution (HBSS). The recovered lavage fluid was centrifuged at $120 \times \boldsymbol{g}$ for $5 \mathrm{~min}$ at $4^{\circ} \mathrm{C}$. The cell pellet was suspended with a defined volume $(200 \mu \mathrm{L} / \mathrm{sample})$ of HBSS. The total leukocyte count in the lavage fluid was determined by staining with Turk's solution. For differential cell counts, BAL cells were stained with Diff-Quik solution (Sysmex International Reagents, Kobe, Japan). A minimum of 200 cells were counted under a microscope and, based on their morphological criteria, classified as macrophages, lymphocytes, neutrophils, or eosinophils. Furthermore, the numbers of MWCNT-positive macrophages in BALF were counted relative to the total number of macrophages to estimate the 
persistence of MWCNT in the lung phagocyte population.

Histological Analysis The left lungs were fixed in 10\% neutral-buffered formalin, then dissected, embedded in paraffin, and cut $4-\mu \mathrm{m}$ thick. Sections were stained with hematoxylin and eosin (H\&E) and periodic acid-Schiff (PAS).

Each section was scored on scale of 0 to 4 with increments of 0.5 by a blinded observer for inflammation (H\&E) and goblet cell hyperplasia (PAS).

Measurement of OVA-Specific IgE, IgG1, and IgG2a OVA-specific IgE, IgG1, and IgG2a antibodies in serum were measured by enzyme-linked immunosorbent assay (ELISA), as described. ${ }^{20)}$ OVA-specific IgE antibody in serum was detected using plates coated with anti-mouse IgE antibody and adding biotin-labeled OVA. Streptoavidin-horseradish peroxidase was added, the plate was developed with 3,3',5,5'-tetramethylbenzidine solution (Wako Pure Chemical) as the substrate, and measurements were made at $450 \mathrm{~nm}$ using a microplate reader after stopping the reaction with sulfuric acid. Values for serum OVA-specific IgE were expressed as absorbance units. Serum samples were diluted at 1:5.

OVA-specific IgG1 or IgG2a was detected using plates coated with OVA and adding alkaline phosphate-conjugated anti-mouse IgG1 or IgG2a, respectively. The plates were developed with $p$-nitrophenyl phosphate and read at $405 \mathrm{~nm}$ using a microplate reader. Values for serum OVA-specific IgG1 and IgG2a were expressed as absorbance units. Serum samples were diluted at 1:1000 and 1:20 for IgG1 and IgG2a, respectively.

Measurement of Cytokines and C3a Levels of cytokines in lung tissue and C3a in BALF $24 \mathrm{~h}$ after the fourth challenge were measured by ELISA as described. ${ }^{21)}$ The frozen right lobe (after BAL) was homogenized in $1 \mathrm{~mL}$ T-PER tissue protein extraction reagent (Thermo Scientific, Rockford, IL, U.S.A.) containing a Complete Mini Protease Inhibitor Cocktail tablet (Roche, Mannheim, Germany; 1 tablet/10 mL T-PER stock reagent). Lung homogenates were centrifuged at $9000 \times \boldsymbol{g}$ for $10 \mathrm{~min}$ at $4^{\circ} \mathrm{C}$. IL-4, IL-5, IL-13 (R\&D Systems, Minneapolis, MN, U.S.A.) and IL-17 (BioLegend, San Diego, CA, U.S.A.) in supernatants of lung homogenates were measured using quantitative colormetric sandwich ELISA kits.

$\mathrm{C} 3 \mathrm{a}$ in BALF was detected using plates coated with rat anti-mouse C3a antibody (BD Biosciences, San Diego, CA, U.S.A.) and adding biotin-labeled rat anti-mouse C3a antibody (BD Biosciences). Alkaline phosphatase-conjugated antibiotin was added, the plate was developed with $p$-nitrophenyl phosphate, and measurements were made at $405 \mathrm{~nm}$ using a microplate reader. The value for $\mathrm{C} 3 \mathrm{a}$ in BALF was expressed as absorbance units.

Statistical Analyses Statistical analyses were performed with one-way analysis of variance (ANOVA). If significant differences were detected, individual group differences were determined by a Bonferroni-Dunn test. A $p$ value of $<0.05$ was considered significant.

\section{RESULTS}

Effect of MWCNT on Early- and Late-Phase Increases in Airway Resistance after the Antigen Challenges We have previously reported that the first antigen challenge caused a swift elevation of sRaw that peaked at $10 \mathrm{~min}$, but no late response was induced in mice systemically sensitized with OVA+alum. ${ }^{16)}$ Therefore, we investigated the effect of sensitization by the combination of MWCNT and OVA on the first antigen-induced early-phase increase in airway resistance by measuring sRaw at $10 \mathrm{~min}$. The first administration of antigen dose-dependently significantly induced the earlyphase increase in airway resistance in OVA+MWCNT0.1 and OVA+MWCNT1 groups compared with in the control, MWCNT (0.1 or 1), and OVA+Tween groups, although the response in mice sensitized with OVA alone or OVA+MWCNT0.01 was only slightly induced after the challenge (Fig. 1Ba). Furthermore, MWCNT-alone administration did not induce a response at any dose. The extent of early responses in OVA+MWCNT1 groups was comparable to that in mice systemically sensitized with OVA+alum (Fig. 1Ba).

Fourth antigen challenge significantly induced not only early but also late increases in airway resistance, peaking $10 \mathrm{~min}$ and $3 \mathrm{~h}$ later, in OVA+MWCNT0.1 and OVA+MWCNT1 groups (Fig. 1Bb), although no responses were observed in other groups except for the OVA+alum group (Fig. 1Bb). Furthermore, the extent of early and late increases in airway resistance in the OVA+MWCNT1 group was comparable to that in mice systemically sensitized with OVA+alum.

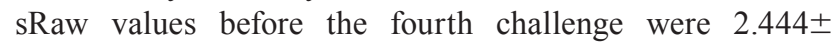
0.045 in control, $2.440 \pm 0.050$ in MWCNT0.01, 2.450 \pm 0.048 in MWCNT0.1, 2.422 \pm 0.065 in MWCNT1, 2.411 \pm 0.052 in OVA + saline, $2.405 \pm 0.062$ in OVA+Tween, $2.467 \pm 0.065$ in OVA+MWCNT0.01, 2.436 \pm 0.067 in OVA+MWCNT0.1, and $2.495 \pm 0.057$ in OVA+MWCNT1 groups. Throughout the above experiment, no significant differences in sRaw before the challenges were found among the groups.

Effect of MWCNT on Inflammatory Cells in BALF after the Fourth Antigen Challenge Figure 2A shows inflammatory cells in BALF of mice sensitized with MWCNT and OVA. Consistent with inflammatory cells in BALF of the OVA+alum group, numbers of inflammatory cells, such as macrophages, lymphocytes, neutrophils, and eosinophils were significantly increased $24 \mathrm{~h}$ after the fourth challenge in the OVA+MWCNT0.1 and OVA+MWCNT1 groups compared with control and OVA+Tween groups, and the increase was in a dose-dependent manner; furthermore, the number of lymphocytes and eosinophils in OVA+MWCNT1 groups was higher than in MWCNT1 groups. Additionally, MWCNT 0.1 and MWCNT1 groups showed an increase in macrophages and neutrophils, but not lymphocytes and eosinophils, compared with the control group.

On the other hand, MWCNT-negative and -positive macrophages in BALF were easily identified by light microscopy, as shown in Figs. $2 \mathrm{Ba}, \mathrm{Bb}$, respectively. In MWCNT0.1 and MWCNT1 groups, $40-70 \%$ of the total number of macrophages contained MWCNT on day 36; however, there were no differences in the relative percentages of MWCNT-positive macrophages between MWCNT and OVA+MWCNT groups (Fig. 2Bc).

Effect of MWCNT on Airway Inflammation and Goblet Cells in the Lung after the Fourth Antigen Challenge As defined by histological analysis using H\&E staining, little leukocyte recruitment was observed $24 \mathrm{~h}$ after the fourth challenge in the control group (Fig. 3Aa). In contrast, there was marked infiltration of leukocytes around the blood vessels and airways $24 \mathrm{~h}$ after the fourth challenge in MWCNT1, OVA+Tween, and OVA+MWCNT1 groups 


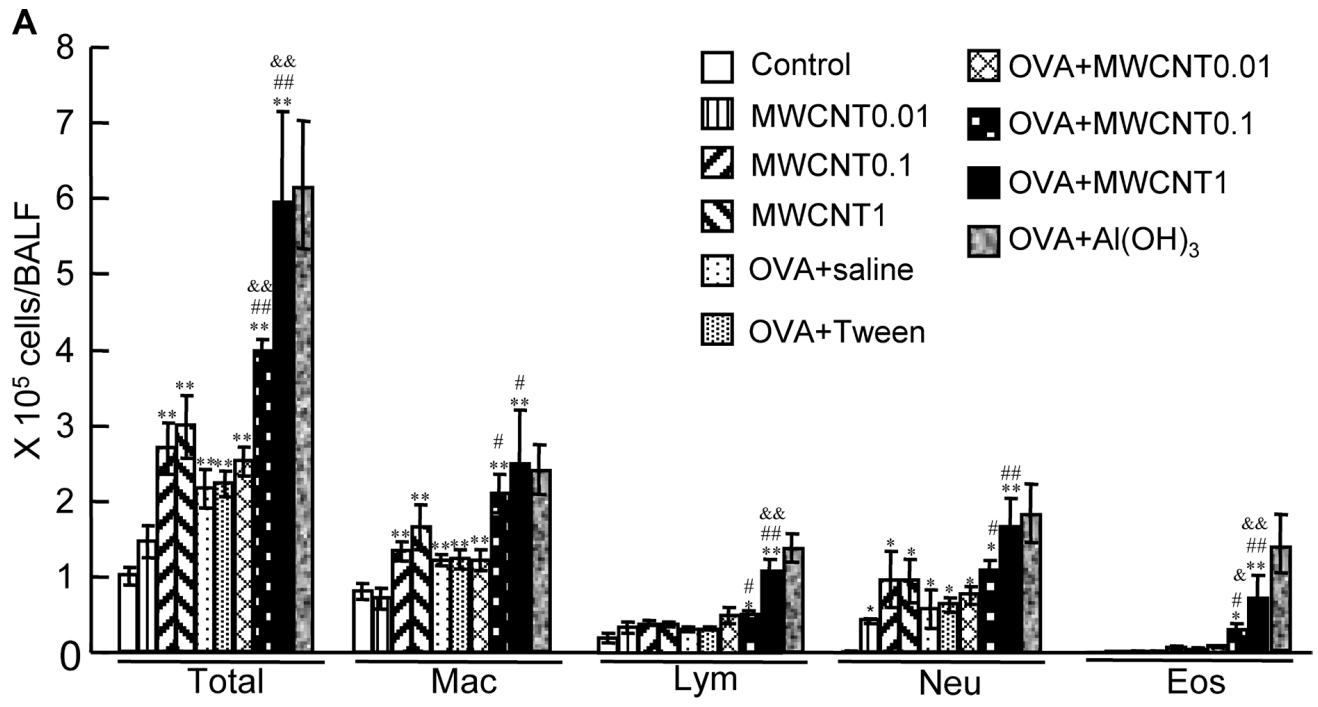

B OVA+Tween

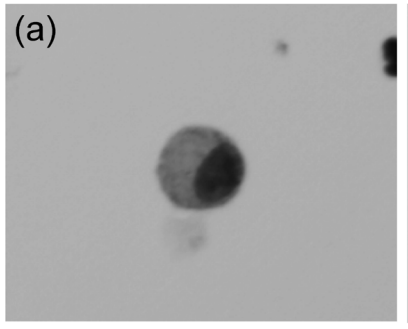

OVA+MWCNT1

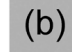

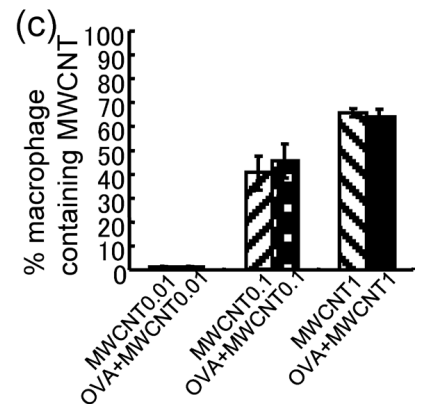

Fig. 2. Effect of MWCNT on Inflammatory Cells in BALF after the Fourth Antigen Challenge

(A) Changes in inflammatory cell numbers in BALF $24 \mathrm{~h}$ after the fourth challenge in mice sensitized with MWCNT and OVA. (B) Persistence of MWCNT in macrophages $24 \mathrm{~h}$ after the fourth challenge in MWCNT and OVA+MWCNT groups. Each value is the mean \pm S.E.M. of 5-7 animals. $* p<0.05$ and $* * p<0.01$ compared with control group. ${ }^{\#} p<0.05$ and ${ }^{\# \#} p<0.01$ compared with OVA+Tween group. ${ }^{\&} p<0.05$ and ${ }^{\& \&} p<0.01$ compared with MWCNT group. Total, all cells, Mac, macrophages; Lym, lymphocytes; Neu, neutrophils; Eos, eosinophils.

(Figs. 3Ab-d). Furthermore, the infiltration of leukocytes in OVA+MWCNT0.1 and OVA+MWCNT1 groups was observed compared with control, MWCNT (0.1 or 1$)$, and OVA+Tween groups, and the increase was dose-dependent (Fig. 3Ae).

Additionally, we performed a histological examination with PAS staining for the detection of goblet cells. In the lungs of MWCNT1, OVA+Tween, and OVA+MWCNT1 groups, goblet cell hyperplasia was observed $24 \mathrm{~h}$ after the fourth challenge (Figs. 3Bb-d), although goblet cell hyperplasia was not observed in the control group (Fig. 3Ba). Furthermore, more increased goblet cell hyperplasia in OVA+MWCNT0.1 and OVA+MWCNT1 groups was observed compared with the control, MWCNT (0.1 or 1), and OVA+Tween groups, and the increase was in a dose-dependent manner (Fig. 3Be).

Effect of MWCNT on Production of Antigen-Specific Antibodies (IgE, IgG1, and IgG2a) and Cytokines after the Fourth Antigen Challenge Figures $4 \mathrm{~A}-\mathrm{C}$ show the production of OVA-specific IgE, IgG1, and IgG2a in the serum of mice sensitized with MWCNT and OVA, respectively. The production of $\operatorname{IgE}$ and $\operatorname{IgG} 2 \mathrm{a}$ was not increased in OVA+Tween group in comparison with the control group, although IgG1 was slightly significantly increased. In contrast, consistent with the findings in mice systemically sensitized with OVA+alum, the fourth administration of antigen in the
OVA+MWCNT1 group significantly increased the production of IgE, IgG1, and IgG2a compared with control, MWCNT1, and OVA+Tween groups (Fig. 4).

IL-4, IL-5, IL-13 (Fig. 5A), and IL-17 (Fig. 5B) in lung tissue, and $\mathrm{C} 3 \mathrm{a}$ (Fig. 5C) in BALF $24 \mathrm{~h}$ after the fourth challenge in OVA+MWCNT1 groups were significantly increased in comparison with control, MWCNT1, and OVA+Tween groups. In addition, the levels of IL-13 in MWCNT1 and OVA+Tween groups were significantly increased compared with the control group (Fig. 5Ac).

\section{DISCUSSION}

In the present study, when mice sensitized by a combination of MWCNT and OVA received repeated antigen challenges, the early increase in airway resistance at the first challenge, and not only the early but also a late response at the fourth challenge were potently aggravated; furthermore, airway inflammation and goblet cell hyperplasia in the lungs, and increased levels of OVA-specific IgE, IgG1, and IgG2a in serum were observed. These findings suggest that sensitization with MWCNT and antigen can exacerbate allergic asthmatic responses associated with increased levels of antigen specific antibodies. 

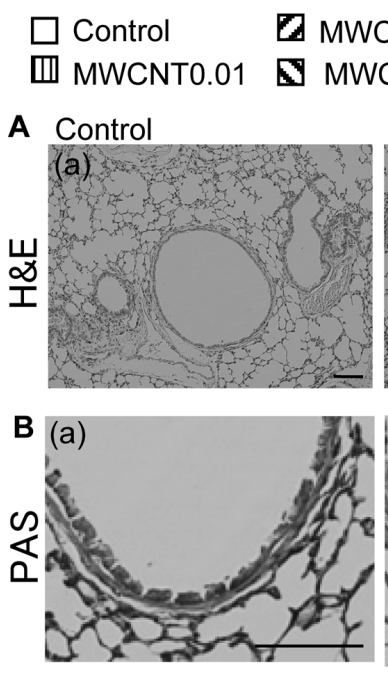

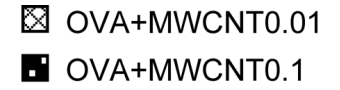

OVA+Tween
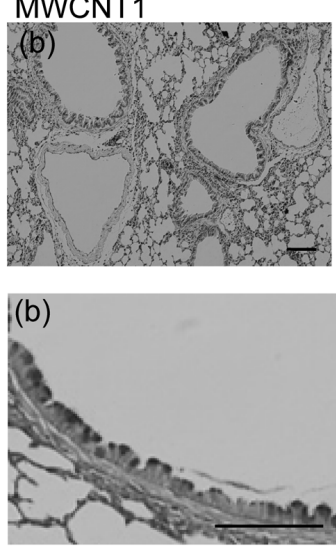
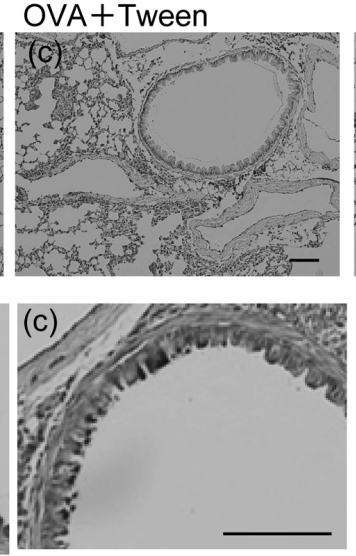

OVA+MWCNT1

Q OVA+AI $(\mathrm{OH})_{3}$
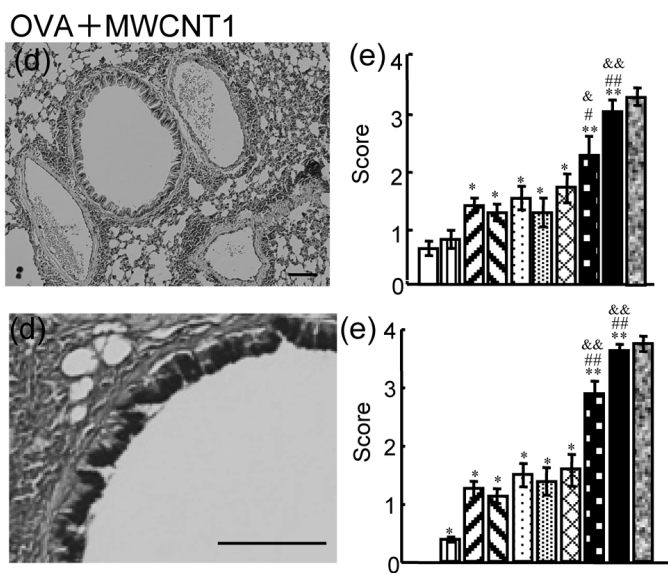

Fig. 3. Effect of MWCNT on Airway Inflammation and Goblet Cell Hyperplasia in Lungs after the Fourth Antigen Challenge

(A) Changes in inflammation (H\&E) in the lungs $24 \mathrm{~h}$ after the fourth challenge in mice sensitized with MWCNT and OVA. Bar shows $100 \mu$ m. Histological appearance was scored for inflammation (e). (B) Changes in goblet cell (PAS) in the lungs $24 \mathrm{~h}$ after the fourth challenge. Bar shows $100 \mu \mathrm{m}$. Histological appearance was scored for goblet cell hyperplasia (e). Each value is the mean \pm S.E.M. of $5-7$ animals. ${ }^{*} p<0.05$ and ${ }^{* *} p<0.01$ compared with control group. ${ }^{\sharp} p<0.05$ and ${ }^{\# \#} p<0.01$ compared with OVA+Tween group. ${ }^{\&} p<0.05$ and ${ }^{\& \&} p<0.01$ compared with MWCNT group.
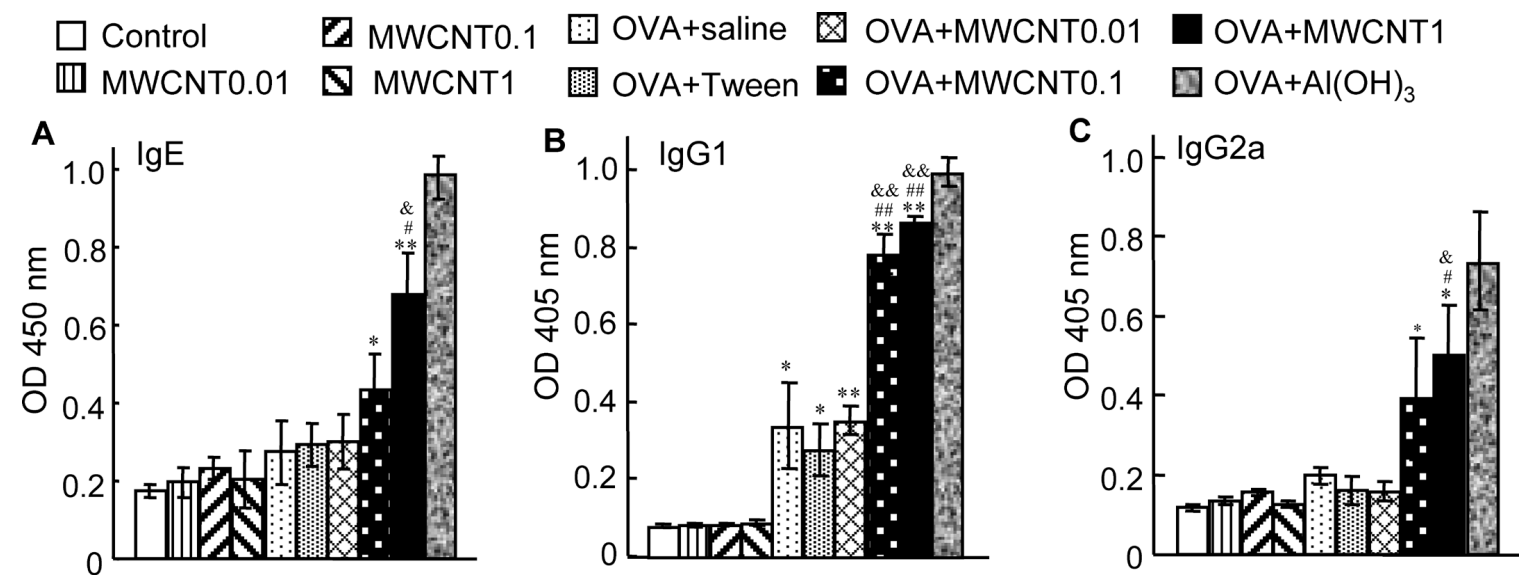

Fig. 4. Effect of MWCNT on the Production of Antigen-Specific IgE, IgG1, and IgG2a after the Fourth Antigen Challenge

(A-C) Levels of OVA-specific IgE (A), IgG1 (B), and IgG2a (C) in serum $24 \mathrm{~h}$ after the fourth challenge in mice sensitized with MWCNT and OVA. Each value is the mean \pm S.E.M. of 5-7 animals. ${ }^{*} p<0.05$ and ${ }^{* *} p<0.01$ compared with control group. ${ }^{\#} p<0.05$ and ${ }^{\# \#} p<0.01$ compared with OVA+Tween group. ${ }^{\&} p<0.05$ and ${ }^{\& \&} p<0.01$ compared with MWCNT group.

It has been reported that nano-sized particles, including $\mathrm{TiO}_{2}$ and carbon black, have more prominent adjuvant effects on allergen-specific responses with $\mathrm{Ig}$ production $^{22-24)}$; however, latex nanoparticles do not facilitate these responses. ${ }^{25}$ ) These previous observations suggest that each nano-level particle has different effects on this pathology, which may depend on their characteristics. Based on these reports, we proposed that MWCNT exposure may be a risk factor for the development of allergic asthma. In this study, sensitization with MWCNT and antigen increased the production of antigen-specific IgE, IgG1, and IgG2a in serum in comparison with mice administered with antigen or MWCNT alone. Thus, MWCNT exhibited adjuvant activity for antigen-specific antibodies.

Antigen-presenting cells (APC), including dendritic cells and macrophages, play fundamental roles in the pathogenesis of asthma. ${ }^{26,27)}$ APC-mediated phagocyte and subsequent antigen presentation for T-cells is the first step in both primary and secondary immune responses; in particular, dendritic cells are recognized to be professional APC, exhibiting potent antigen-presenting ability. ${ }^{28,29)}$ It has been reported that carbon black nanoparticles enhance the maturation and function of mouse bone marrow-derived dendritic cells in vitro, ${ }^{30)}$ and intrapulmonary APC activation with asthma pathophysiology in vivo, ${ }^{31)}$ indicating that the effects of MWCNT on allergic asthma can be mediated, at least in part, through the activation of APC. On the other hand, we demonstrated that the same levels of macrophages containing MWCNT in both MWCNT and MWCNT+antigen groups were observed. In addition, the amount of allergen carried on the particles is dependent on the particle surface area ${ }^{32}$ and MWCNT share particle characteristics, such as a nano-sized diameter and a large surface area, with ultrafine particles of urban air pollution, ${ }^{33)}$ suggesting that the large particle surface area of MWCNT is likely to augment the carried amount of allergen and thus the cellular response.

As expected, sensitization with MWCNT and antigen 
DControl $\mathbf{Q}$ MWCNT1 圈OVA+Tween DOVA+MWCNT1

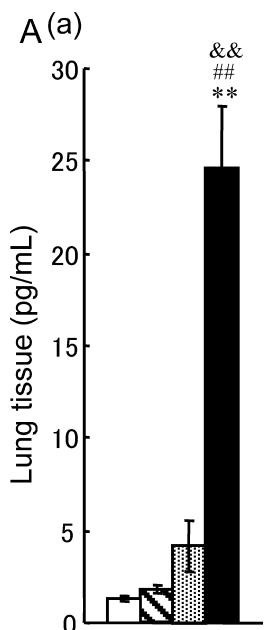

IL-4 (b)

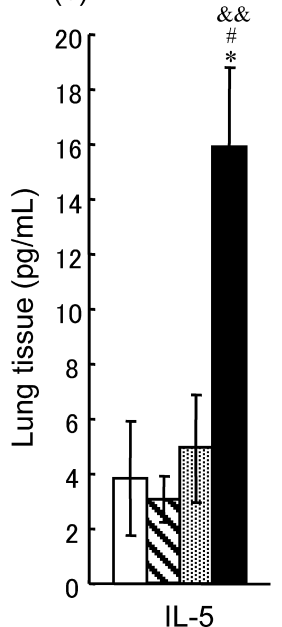

(c)

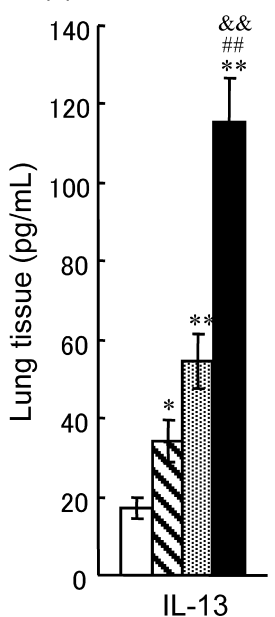

B

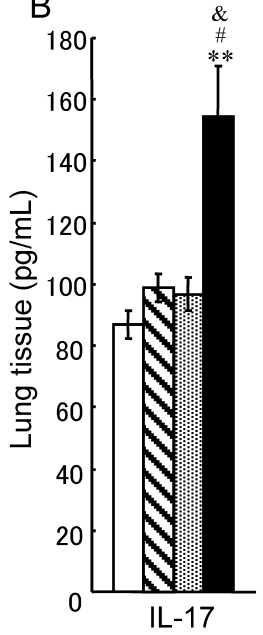

C

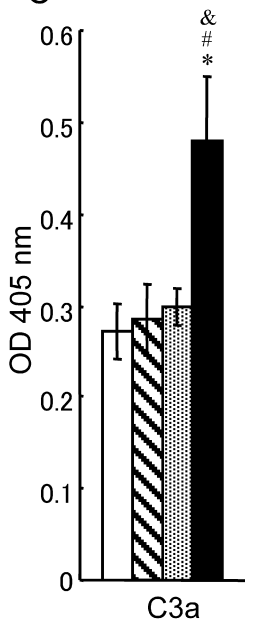

Fig. 5. Effect of MWCNT on the Production of Cytokines (IL-4, IL-5, IL-13, and IL-17) in the Lungs and C3a in BALF after the Fourth Challenge

(A) Levels of IL-4 (a), IL-5 (b), and IL-13 (c) in lung tissue $24 \mathrm{~h}$ after the fourth challenge in mice sensitized with MWCNT and OVA. (B) Levels of IL-17 in lung tissue $24 \mathrm{~h}$ after the fourth challenge. (C) Levels of C3a in BALF $24 \mathrm{~h}$ after the fourth challenge. Each value is the mean \pm S.E.M. of $5-7$ animals. $* p<0.05$ and $* * p<0.01$ compared with control group. ${ }^{\#} p<0.05$ and ${ }^{\# \#} p<0.01$ compared with OVA+Tween group. ${ }^{\&} p<0.05$ and ${ }^{\& \&} p<0.01$ compared with MWCNT group.

induced airway inflammation, such as the infiltration of eosinophils and neutrophils, and a late-phase increase in airway resistance by repeated antigen challenge. We have demonstrated that the depletion of neutrophils by anti-Gr-1 mAb greatly suppressed the late-phase increase in airway resistance in OVA+alum sensitized mice. ${ }^{34)}$ Furthermore, in the present study, we observed the infiltration of neutrophils in BALF of mice sensitized with MWCNT and antigen, indicating that the late-phase increase in airway resistance may be mediated by neutrophilic airway inflammation. Regarding the mechanisms underlying the recruitment of neutrophils to inflamed sites, we have reported that complement C3a-mediated IL-17 plays an important role in the development of a late response via neutrophil accumulation in mice sensitized with anti-OVA IgE monoclonal antibody. ${ }^{21)}$ Therefore, in the present study, we found increased levels of $\mathrm{C} 3 \mathrm{a}$ in BALF and production of IL-17 in lung tissue, suggesting that C3a-induced IL-17 contributes to the development of a late-phase increase in airway resistance through neutrophilic airway inflammation in mice sensitized with MWCNT and antigen; however, the mechanism of C3a production in this study is unclear. First, it is possible that in addition to activating the complement through the classical pathway, the antigen may directly activate $\mathrm{C} 3 \mathrm{via}$ an alternative pathway. Another possibility is that a neutral tryptase released from mast cells or pulmonary macrophages proteolytically cleaves $\mathrm{C} 3$ to generate $\mathrm{C} 3 \mathrm{a}^{35,36)}$ Thus, the antigen-triggered release of tryptase in mice sensitized with MWCNT and antigen could lead to $\mathrm{C} 3$ a production without typical activation of the entire complement cascade. On the other hand, the important role of eosinophils in the immunopathogenesis of asthma was shown in studies using eosinophil-deficient mice that markedly attenuated the development of asthmatic responses. ${ }^{37)}$ Thus, we showed that sensitization with MWCNT and antigen induced not only a late response but also the infiltration of eosinophils and neutrophils into the lungs, raising the possibility that eosinophilia and/or neutrophilia may contribute to the development of a late increase in airway resistance.

In this sensitization with MWCNT and antigen, an earlyphase increase in airway resistance was observed at the first and fourth challenge. It has been reported that mice sensitized with anti-OVA IgE monoclonal antibody showed an early response $10 \mathrm{~min}$ after the antigen challenge, and the level of mouse mast cell protease- 1 in serum $30 \mathrm{~min}$ after the antigen challenge was increased. ${ }^{20)}$ In mice sensitized with MWCNT and OVA, an increased level of IgE in serum was observed, suggesting that the early response may be IgE-dependent, probably through the activation of mast cells in the lung. Furthermore, the early response might have been influenced by not only IgE but also IgG1 and/or IgG2a because IgG1 and/or IgG2a production in serum was significantly observed in mice sensitized with MWCNT and antigen.

Goblet cell hyperplasia, a characteristic feature of allergic asthma, ${ }^{38-40)}$ was induced by co-sensitization with MWCNT and OVA. IL-4 and IL-13 are known to induce goblet cell hyperplasia in vivo. ${ }^{41,42)}$ In the present study, airway production of IL-4 and IL-13 was also induced by sensitization, suggesting that IL-4 and IL-13 are critical for the development of goblet cell hyperplasia in mice sensitized with MWCNT and OVA. In addition, it has been reported that multiple treatments with a $\mathrm{C} 3 \mathrm{a}$ receptor antagonist during repeated antigen challenge also inhibited goblet cell hyperplasia in mice sensitized with OVA+alum, ${ }^{16)}$ and $\mathrm{C} 3 \mathrm{a}$ induced goblet cell hyperplasia in the lung, ${ }^{43)}$ suggesting that not only Th2-type cytokines but also $\mathrm{C} 3 \mathrm{a}$ are important to goblet cell hyperplasia in mice sensitized with MWCNT and OVA.

Collectively, through these experiments, we demonstrated that sensitization with MWCNT and antigen can exacerbate the antigen-induced biphasic increase in airway resistance, airway inflammation, goblet cell hyperplasia, and the production of antigen-specific antibodies (IgE, IgG1, and $\operatorname{IgG} 2 \mathrm{a}$ ) in serum. This study highlights the risk of exposure to a combination of MWCNT and antigen from occupational and environmental exposure. 
Acknowledgements We thank Akihiro Hamaguchi (Kobe Pharmaceutical University) for assistance with sample measurements. Part of this work was supported by a Grant-in-Aid for Young Scientists (B) (23790164, to N. Mizutani) from the Ministry of Education, Culture, Sports, Science and Technology of Japan.

\section{REFERENCES}

1) Cohn L, Elias JA, Chupp GL. Asthma: mechanisms of disease persistence and progression. Annu. Rev. Immunol., 22, 789-815 (2004).

2) Robinson DS, Hamid Q, Ying S, Tsicopoulos A, Barkans J, Bentley AM, Corrigan C, Durham SR, Kay AB. Predominant TH2-like bronchoalveolar T-lymphocyte population in atopic asthma. N. Engl. J. Med., 326, 298-304 (1992).

3) Aikawa T, Shimura S, Sasaki H, Ebina M, Takishima T. Marked goblet cell hyperplasia with mucus accumulation in the airways of patients who died of severe acute asthma attack. Chest, 101, 916-921 (1992).

4) Umetsu DT, McIntire JJ, Akbari O, Macaubas C, DeKruyff RH. Asthma: an epidemic of dysregulated immunity. Nat. Immunol., 3 , 715-720 (2002).

5) Matsui EC, Hansel NN, McCormack MC, Rusher R, Breysse PN, Diette GB. Asthma in the inner city and the indoor environment. Immunol. Allergy Clin. North Am., 28, 665-686, x (2008).

6) Service RF. Nanotoxicology. Nanotechnology grows up. Science, 304, 1732-1734 (2004).

7) Sun YP, Fu K, Lin Y, Huang W. Functionalized carbon nanotubes: properties and applications. Acc. Chem. Res., 35, 1096-1104 (2002).

8) Mitchell LA, Gao J, Wal RV, Gigliotti A, Burchiel SW, McDonald JD. Pulmonary and systemic immune response to inhaled multiwalled carbon nanotubes. Toxicol. Sci., 100, 203-214 (2007).

9) Murr LE, Garza KM, Soto KF, Carrasco A, Powell TG, Ramirez DA, Guerrero PA, Lopez DA, Venzor J 3rd. Cytotoxicity assessment of some carbon nanotubes and related carbon nanoparticle aggregates and the implications for anthropogenic carbon nanotube aggregates in the environment. Int. J. Environ. Res. Public Health, 2, 31-42 (2005).

10) Magrez A, Kasas S, Salicio V, Pasquier N, Seo JW, Celio M, Catsicas S, Schwaller B, Forró L. Cellular toxicity of carbon-based nanomaterials. Nano Lett., 6, 1121-1125 (2006).

11) Manna SK, Sarkar S, Barr J, Wise K, Barrera EV, Jejelowo O, Rice-Ficht AC, Ramesh GT. Single-walled carbon nanotube induces oxidative stress and activates nuclear transcription factor-kappaB in human keratinocytes. Nano Lett., 5, 1676-1684 (2005).

12) Maynard AD, Baron PA, Foley M, Shvedova AA, Kisin ER, Castranova V. Exposure to carbon nanotube material: aerosol release during the handling of unrefined single-walled carbon nanotube material. J. Toxicol. Environ. Health A, 67, 87-107 (2004).

13) Muller J, Huaux F, Moreau N, Misson P, Heilier JF, Delos M, Arras M, Fonseca A, Nagy JB, Lison D. Respiratory toxicity of multi-wall carbon nanotubes. Toxicol. Appl. Pharmacol., 207, 221-231 (2005).

14) Shvedova AA, Kisin ER, Mercer R, Murray AR, Johnson VJ, Potapovich AI, Tyurina YY, Gorelik O, Arepalli S, Schwegler-Berry D, Hubbs AF, Antonini J, Evans DE, Ku BK, Ramsey D, Maynard A, Kagan VE, Castranova V, Baron P. Unusual inflammatory and fibrogenic pulmonary responses to single-walled carbon nanotubes in mice. Am. J. Physiol. Lung Cell. Mol. Physiol., 289, L698-L708 (2005).

15) Nabe T, Zindl CL, Jung YW, Stephens R, Sakamoto A, Kohno S, Atkinson TP, Chaplin DD. Induction of a late asthmatic response associated with airway inflammation in mice. Eur. J. Pharmacol., 521, 144-155 (2005)

16) Mizutani N, Nabe $T$, Yoshino $\mathrm{S}$. Complement $\mathrm{C} 3$ a regulates late asthmatic response and airway hyperresponsiveness in mice. $J$. Immunol., 183, 4039-4046 (2009).
17) Wick P, Manser P, Limbach LK, Dettlaff-Weglikowska U, Krumeich F, Roth S, Stark WJ, Bruinink A. The degree and kind of agglomeration affect carbon nanotube cytotoxicity. Toxicol. Lett., 168, 121-131 (2007).

18) Fraczek-Szczypta A, Menaszek E, Blazewicz S. Some observations on carbon nanotubes susceptibility to cell phagocytosis. J. Nanomater., 2011, 473516/1-8 (2011).

19) Pennock BE, Cox CP, Rogers RM, Cain WA, Wells JH. A noninvasive technique for measurement of changes in specific airway resistance. J. Appl. Physiol., 46, 399-406 (1979).

20) Mizutani N, Goshima H, Nabe T, Yoshino S. Establishment and characterization of a murine model for allergic asthma using allergen-specific IgE monoclonal antibody to study pathological roles of IgE. Immunol. Lett., 141, 235-245 (2012).

21) Mizutani N, Goshima H, Nabe T, Yoshino S. Complement C3ainduced IL-17 plays a critical role in an IgE-mediated late-phase asthmatic response and airway hyperresponsiveness via neutrophilic inflammation in mice. J. Immunol., 188, 5694-5705 (2012).

22) de Haar C, Hassing I, Bol M, Bleumink R, Pieters R. Ultrafine carbon black particles cause early airway inflammation and have adjuvant activity in a mouse allergic airway disease model. Toxicol. Sci., 87, 409-418 (2005).

23) Inoue $K$, Takano $H$, Yanagisawa $R$, Sakurai $M$, Ichinose $T$, Sadakane K, Yoshikawa T. Effects of nano particles on antigen-related airway inflammation in mice. Respir. Res., 6, 106 (2005).

24) de Haar C, Hassing I, Bol M, Bleumink R, Pieters R. Ultrafine but not fine particulate matter causes airway inflammation and allergic airway sensitization to co-administered antigen in mice. Clin. Exp. Allergy, 36, 1469-1479 (2006).

25) Inoue $K$, Takano H, Yanagisawa R, Koike E, Shimada A. Size effects of latex nanomaterials on lung inflammation in mice. Toxicol. Appl. Pharmacol., 234, 68-76 (2009).

26) Upham JW. The role of dendritic cells in immune regulation and allergic airway inflammation. Respirology, 8, 140-148 (2003).

27) Kato T, Tada-Oikawa S, Takahashi K, Saito K, Wang L, Nishio A, Hakamada-Taguchi R, Kawanishi S, Kuribayashi K. Endocrine disruptors that deplete glutathione levels in APC promote Th2 polarization in mice leading to the exacerbation of airway inflammation. Eur. J. Immunol., 36, 1199-1209 (2006).

28) Rossi M, Young JW. Human dendritic cells: potent antigen-presenting cells at the crossroads of innate and adaptive immunity. $J$. Immunol., 175, 1373-1381 (2005).

29) de Jong EC, Smits HH, Kapsenberg ML. Dendritic cell-mediated T cell polarization. Springer Semin. Immunopathol., 26, 289-307 (2005).

30) Koike E, Takano H, Inoue K, Yanagisawa R, Kobayashi T. Carbon black nanoparticles promote the maturation and function of mouse bone marrow-derived dendritic cells. Chemosphere, 73, 371-376 (2008).

31) Koike E, Takano H, Inoue KI, Yanagisawa R, Sakurai M, Aoyagi H, Shinohara R, Kobayashi T. Pulmonary exposure to carbon black nanoparticles increases the number of antigen-presenting cells in murine lung. Int. J. Immunopathol. Pharmacol., 21, 35-42 (2008).

32) Ormstad H, Johansen BV, Gaarder PI. Airborne house dust particles and diesel exhaust particles as allergen carriers. Clin. Exp. Allergy, 28, 702-708 (1998).

33) Pope CA 3rd, Dockery DW. Health effects of fine particulate air pollution: lines that connect. J. Air Waste Manag. Assoc., 56, 709742 (2006)

34) Nabe T, Hosokawa F, Matsuya K, Morishita T, Ikedo A, Fujii M, Mizutani N, Yoshino S, Chaplin DD. Important role of neutrophils in the late asthmatic response in mice. Life Sci., 88, 1127-1135 (2011).

35) Schwartz LB, Kawahara MS, Hugli TE, Vik D, Fearon DT, Austen KF. Generation of C3a anaphylatoxin from human C3 by human mast cell tryptase. J. Immunol., 130, 1891-1895 (1983). 
36) Mulligan MS, Schmid E, Beck-Schimmer B, Till GO, Friedl HP, Brauer RB, Hugli TE, Miyasaka M, Warner RL, Johnson KJ, Ward PA. Requirement and role of C5a in acute lung inflammatory injury in rats. J. Clin. Invest., 98, 503-512 (1996).

37) Lee JJ, Dimina D, Macias MP, Ochkur SI, McGarry MP, O’Neill KR, Protheroe C, Pero R, Nguyen T, Cormier SA, Lenkiewicz E, Colbert D, Rinaldi L, Ackerman SJ, Irvin CG, Lee NA. Defining a link with asthma in mice congenitally deficient in eosinophils. Science, 305, 1773-1776 (2004).

38) Aikawa $T$, Shimura S, Sasaki H, Ebina M, Takishima T. Marked goblet cell hyperplasia with mucus accumulation in the airways of patients who died of severe acute asthma attack. Chest, 101, 916-921 (1992).

39) Dunnill MS, Massarella GR, Anderson JA. A comparison of the quantitative anatomy of the bronchi in normal subjects, in status asthmaticus, in chronic bronchitis, and in emphysema. Thorax, 24, 176-179 (1969).
40) Shimura S, Andoh Y, Haraguchi M, Shirato K. Continuity of airway goblet cells and intraluminal mucus in the airways of patients with bronchial asthma. Eur. Respir. J., 9, 1395-1401 (1996).

41) Rankin JA, Picarella DE, Geba GP, Temann UA, Prasad B, DiCosmo B, Tarallo A, Stripp B, Whitsett J, Flavell RA. Phenotypic and physiologic characterization of transgenic mice expressing interleukin 4 in the lung: lymphocytic and eosinophilic inflammation without airway hyperreactivity. Proc. Natl. Acad. Sci. U.S.A., 93, 7821-7825 (1996).

42) Zhu Z, Homer RJ, Wang Z, Chen Q, Geba GP, Wang J, Zhang Y, Elias JA. Pulmonary expression of interleukin-13 causes inflammation, mucus hypersecretion, subepithelial fibrosis, physiologic abnormalities, and eotaxin production. J. Clin. Invest., 103, 779-788 (1999).

43) Dillard P, Wetsel RA, Drouin SM. Complement C3a regulates Muc5ac expression by airway Clara cells independently of Th2 responses. Am. J. Respir. Crit. Care Med., 175, 1250-1258 (2007). 